\title{
Evaluation of shear strength of brackets with different dental composites and enamel roughness
}

\author{
Ricardo Danil Guiraldo ${ }^{*}$, Sandrine Bittencourt Berger ${ }^{1}$, Fernando dos Santos Rocha', \\ Gabriela Miranda Rodrigues Pereira ${ }^{1}$, Anderson Rafael Aleixo' ${ }^{1}$ Américo Bortolazzo Correr², \\ Edwin Fernando Ruiz Contreras ${ }^{3}$, Alcides Gonini-Júnior ${ }^{1}$ and Murilo Baena Lopes ${ }^{1}$
}

\section{${ }^{*}$ Correspondence:}

rdguiraldo@gmail.com

${ }^{1}$ Department of Restorative Dentistry, School of Dentistry, University of North Parana UNOPAR, Rua Marselha 183, Londrina CEP 86041-140, PR, Brazil

Full list of author information is available at the end of the article

\begin{abstract}
The objective of this study was to evaluate the enamel roughness and shear bond strength (SBS) of dental composite after removal of metal brackets bonded with different materials (Transbond XT, Filtek Z100, Venus Diamond and Filtek P90). Cleaning and etching were performed in vitro on 60 premolars, which were then divided into four groups $(n=15)$. A metal bracket was bonded to each tooth using one of the four materials. The SBS test was performed in an Instron universal testing machine, using a chisel positioned at the junction interface with a speed of $1.0 \mathrm{~mm} / \mathrm{min}$. After testing the SBS, the teeth were analyzed using the Adhesive Remnant Index (ARI) with a stereomicroscope under $40 \times$ magnification. The remainder of the bonding material was removed with multilaminated carbide bur (FF 9642) and the surface roughness measured. The SBS and roughness data were statistically analyzed. The average SBS for the different groups in this study ranged from 6.13 to $12.72 \mathrm{MPa}$; Transbond XT $(12.57 \mathrm{MPa}$ ) and Filtek Z100 (12.72 MPa) showed the highest values. There were differences between the bonding materials in IRA scores, but no statistically significant difference for roughness. All SBS values were adequate, since none were below the minimum acceptable level (6-8 MPa), however the enamel did not return to the conditions present prior to the bonding of the brackets.
\end{abstract}

Keywords: Composites, Debonding brackets, Shear bond strength, Enamel roughness

\section{Background}

Direct bonding of orthodontic brackets to the labial face of teeth was introduced by Newman [1] in 1965 with the purpose of eliminating metal bands [2]. This only became possible as a result of the concept of enamel etching, introduced by Buonocore [3] in 1955, which enabled orthodontic accessories to be bonded to teeth by means of a high bond-strength adhesive system [2]. Since then, the impact on the bond strength of direct bonding techniques of varying the adhesive system [4-8], type and time of enamel etching $[7,9]$, and types of orthodontic brackets $[10,11]$ has been a subject of active investigation.

In routine orthodontic practice, it is essential to obtain a reliable bond between an orthodontic attachment and tooth enamel. In bonding orthodontic brackets to the

(c) 2016 The Author(s). This article is distributed under the terms of the Creative Commons Attribution 4.0 International License (http://creativecommons.org/licenses/by/4.0/), which permits unrestricted use, distribution, and reproduction in any medium, provided you give appropriate credit to the original author(s) and the source, provide a link to the Creative Commons license, and indicate if changes were made. 
enamel surface, composite resins play an important role in bonding results. Filled restorative materials have been used as orthodontic adhesives [12, 13]. The principal drawback of polymeric composite restorative materials remains their high polymerization shrinkage [14]. In addition, polymerization shrinkage of orthodontic adhesives has a pronounced effect on the durability of bonding $[2,15,16]$. Thus, gap formation contributes to microleakage, permitting the passage of bacteria and salivary secretions from the oral cavity $[13,17]$. White spot lesions prevalence and severity were shown to increase with fixed appliance treatment $[13,18,19]$.

The results of this shrinkage have been well documented, with a clinical problem being the development of physical stresses at the restoration interface $[14,20]$ and the type of composite affects the retention of composite restorations in dental cavities [21]. This stress may also occur between the orthodontic attachment and tooth enamel. To address these physical stresses, 3 M ESPE (St. Paul, MN) has introduced silorane, a material reported to have lower shrinkage. Silorane was named to indicate a hybrid compound containing siloxane and oxirane functional groups [22,23]. The siloxane is responsible for the highly hydrophobic nature of silorane, while the cycloaliphatic oxirane functional groups result in lower shrinkage compared with methacrylate-based composites. Oxiranes are cyclic ethers that polymerize through a cationic ring-opening mechanism, in contrast with the free radical polymerization of methacrylates [23, 24]. Venus Diamond (Heraeus Kulzer, Armonk, NY) is a nanohybrid universal composite containing a monomer (TCD-DI-HEA) (Bis-[acryloyloxymethyl] tricyclo[5.2.1.02,6]decane) that is said to combine low shrinkage with low viscosity [25].

Relevant factors in bracket debonding $[26,27]$ and subsequent polishing of the enamel surface [26-28] also have been investigated [29]. Incorrect removal of the brackets or adhesive can lead to permanent damage of the enamel and an extended time for debonding $[26,30]$. The final procedure in returning the enamel surface to its original pretreatment condition involves removal of all attachments and remaining resin from tooth surfaces [31, 32].

Thus, the aim of this study was to evaluate shear strength of metal brackets attached with different dental composites and enamel roughness after debonding and finishing. The null hypotheses were that the shear strength of metal brackets would not differ among groups of teeth treated with different dental composites (1), and that the surface roughness of enamel after debonding and finishing would not differ between groups nor between the treated and sound enamel not subjected to bonding of the metal brackets (2).

\section{Methods}

\section{Specimen preparation}

The project was approved by the Ethics Committee and 60 premolars without cracks or surface defects were collected. The roots were sectioned with a water-cooled diamond saw (Isomet; Buehler Ltd., Lake Bluff, IL, USA) and the crowns embedded in self-curing acrylic resin (Clássico Produtos Odontologicos, São Paulo, SP, Brazil) in polyvinyl chloride tubes, with the buccal face perpendicular to the tube. The vestibular faces of all teeth were cleaned with a rubber cup and non-fluoridated pumice-water slurry (S.S. White, Petrópolis, RJ, Brazil) for $10 \mathrm{~s}$, rinsed with air-water spray for $10 \mathrm{~s}$ and air-dried for $10 \mathrm{~s}$. 
The teeth were divided into 4 groups $(n=15)$, to test each of 4 bonding materials: Transbond XT (3 M Unitek, Monrovia, CA, USA), Filtek Z100 (3 M/ESPE, St. Paul, MN, USA), Venus Diamond (Heraeus Kulzer, Armonk, NY, USA), and e Filtek P90 (Silorane composite; $3 \mathrm{M} / \mathrm{ESPE}$ ). To prepare the teeth for three of the bonding materials (Transbond XT, Filtek Z100 and Venus Diamond), the middle third of the buccal face of each tooth was etched with $35 \%$ phosphoric acid gel (Scotchbond Etching Gel, $3 \mathrm{M} / \mathrm{ESPE}$ ) for $20 \mathrm{~s}$, rinsed with air water spray for $20 \mathrm{~s}$ and air-dried for $20 \mathrm{~s}$. For the Transbond XT bonding material, one layer of Transbond XT Primer (3 M Unitek) was applied to the etched tooth and light-activated for $10 \mathrm{~s}$ using a light-emitting diode (Radii Cal, SDI, Bayswater, Victoria, Australia) set to $1400 \mathrm{~mW} / \mathrm{cm}^{2}$. Standard stainless steel premolar brackets (Morelli Ortodontia, Sorocaba, SP, Brazil) were then positioned and firmly bonded to the tooth using Transbond XT light-cured bonding resin (3 M Unitek), excess removed using a microbrush (KG Sorensen, Cotia, SP-Brazil) and the resin light-activated.

For bonding materials Filtek Z100 and Venus Diamond, one layer of Adper Scotchbond Multi-Purpose Adhesive (3 M ESPE) was applied to the etched tooth and light activated for $10 \mathrm{~s}$. Standard stainless steel premolar brackets were then positioned and firmly bonded to the tooth using Filtek Z100 and Venus Diamond (respectively in each group), excess removed using a microbrush, and the resin light-activated.

For bonding material Filtek P90, one layer of Silorane system adhesive self-etch primer and bond was applied to the unetched tooth and light activated for $10 \mathrm{~s}$. Silorane system bond was then applied and cured in a similar manner. Standard stainless steel premolar brackets were then positioned and firmly bonded to the tooth using Filtek P90, excess removed using a microbrush, and the Filtek P90 light-activated. Light-activation in all groups was carried out with four exposures on each side of the bracket, for total exposure time $40 \mathrm{~s}$.

\section{Bond strength testing and failure analysis}

After $24 \mathrm{~h}$ of the specimen preparation, the shear bond strength (SBS) test was performed using a mechanical testing machine (Model 4411; Instron, Canton, MA, USA) with a knife-edged rod at a crosshead speed of $1.0 \mathrm{~mm} / \mathrm{min}$ until the bond failed. A mounting jig was used to align the tooth-bracket interface parallel to the testing device.

After debonding, the tooth and bracket surfaces were examined with a stereomicroscope (Olympus Corp, Tokyo, Japan) under $40 \times$ magnification. The adhesive remnant index (ARI) [33] was used to classify the failure modes, using the following scores: 0 indicates that no bonding resin remained on the tooth, 1 indicates that less than half of the bonding resin remained on the tooth, 2 indicates that more than half of the bonding resin remained on the tooth and 3 indicates that all bonding resin remained on the tooth, along with a clear impression of the bracket mesh.

\section{Tooth finishing and roughness testing}

To measure the average surface roughness $(\mathrm{Ra})$ of the teeth, a surface roughness tester (SJ-400; Mitutouo, Kawasaki-Shi, Japan) was used at a speed of $0.05 \mathrm{~mm} / \mathrm{s}$ speed, with a length of $1.25 \mathrm{~mm}$ and a cut-off of $0.25 \mathrm{~mm}$. Three measurements in different directions, each offset by $120^{\circ}$, were recorded, and the initial Ra was determined for each tooth 
prior to bracket bonding. After the failure analysis, the teeth were finished with a multilaminated carbide bur (FF 9642; JET, Morrisburg, ON, Canada), at low rpm (rotations per minute) under intermittent water cooling until a visibly smooth and polished surface was obtained (80 s), after which the final Ra was measured.

\section{Statistical analysis}

Statistical analysis was performed using Minitab 16 for Windows 8 (Minitab Inc., State College, USA). SBS mean values were subjected to the D'Agostino-Pearson test for normality; then to a one-way ANOVA and Tukey's range test $(\alpha=0.05)$. The average values of surface roughness $(\mathrm{Ra})$ were subjected to the D'Agostino-Pearson test for normality; then to a two-way ANOVA (bonding materials $\times$ time), and the means were compared using the Bonferroni test $(\alpha=0.05)$.

\section{Results}

The SBS of each group is shown in Table 1. The mean SBS for Transbond XT and Filtek Z100 composites were significantly greater than that of Venus Diamond, which was in turn, significantly greater than that of Filtek P90. The surface roughness test results are depicted in Table 1. After resin removal, the surface roughness did not differ significantly among the groups, and the initial roughness was lower than the final roughness for all composites $(\mathrm{p}>0.05)$.

The ARI scores are shown in Table 2. The mode for the ARI scores were two for the Transbond XT (53.4 \%) and Filtek Z100 (66.7 \%) composites, one for the Filtek P90 (53.4\%) composite and three for Venus Diamond (60.1\%).

\section{Discussion}

In general, populations not only demand restorative treatment, but also demand treatments that improve their esthetic and oral functionality, such as orthodontic treatment [34]. In orthodontic clinical practice, bracket bonding and arch placement can be made in the same visit [35]. Therefore, force can be applied to the bracket within the first hour after bonding [35]. This force can affect adhesive curing and, subsequently, the strength of the bond to the enamel [35]. Thus, orthodontic bonding materials should have optimal physicochemical and mechanical characteristics as well as sufficient bond strength to withstand masticatory forces [36]. Different composites have been suggested for bonding orthodontic brackets [37], including both restorative and orthodontic bonding materials. However, the two major properties of these dental composites that still

Table 1 Bond strength mean values (MPa) and surface roughness ( $\mathrm{Ra}$ ) mean values ( $\mu \mathrm{m})$ and standard deviations () in the experimental groups

\begin{tabular}{lcll}
\hline Composite & Shear bond strength & \multicolumn{2}{l}{ Surface roughness } \\
\cline { 4 - 4 } & & Initial Ra $(\boldsymbol{\mu m})$ & Final $\mathbf{R a}(\boldsymbol{\mu m})$ \\
\hline Transbond XT & $12.57(2.76) \mathrm{A}$ & $0.21(0.04) \mathrm{Aa}$ & $0.33(0.02) \mathrm{Ab}$ \\
Filtek Z100 & $12.72(2.65) \mathrm{A}$ & $0.22(0.03) \mathrm{Aa}$ & $0.32(0.02) \mathrm{Ab}$ \\
Filtek P90 & $6.13(2.02) \mathrm{C}$ & $0.21(0.03) \mathrm{Aa}$ & $0.31(0.01) \mathrm{Ab}$ \\
Venus Diamond & $9.31(1.36) \mathrm{B}$ & $0.22(0.04) \mathrm{Aa}$ & $0.31(0.01) \mathrm{Ab}$ \\
\hline
\end{tabular}

Different uppercase letters in column and lowercase letters in row for surface roughness indicate statistically significant difference $(p>0.05)$ 
Table 2 Frequency distributions of the adhesive remnant index (ARI) scores

\begin{tabular}{llllr}
\hline Composite & ARI scores (\%) & & \\
\cline { 2 - 5 } & $\mathbf{0}$ & $\mathbf{1}$ & $\mathbf{2}$ & $\mathbf{3}$ \\
\hline Transbond XT & 0 & 39.9 & 53.4 & 6.7 \\
Filtek Z100 & 0 & 26.6 & 66.7 & 6.7 \\
Filtek P90 & 6.7 & 53.4 & 26.6 & 13.3 \\
Venus Diamond & 0 & 13.3 & 26.6 & 60.1 \\
\hline
\end{tabular}

The ARI scale has a range between 0 and 3. 0 , indicates that no bonding resin on the tooth; 1 , indicates that less than half of the bonding resin remained on the tooth; 2 , indicates that more than half of the bonding resin remained on the tooth and 3 , indicates that all bonding resin remained on the tooth, with a distinct impression of the bracket mesh

require improvement are their polymerization shrinkage and the related polymerization stress $[13,24]$. Thus, this study evaluated the bonding properties of two low-shrinking composites (Venus Diamond and Filtek P90) and a conventional composite (Filtek Z100) in comparison with a conventional orthodontic composite (Transbond XT) for bonding orthodontic brackets and the surface roughness of enamel after debonding.

The average shear bond strength for the different groups in this study ranged from 6.13 to $12.72 \mathrm{MPa}$ (Table 1). An important factor is whether the bond strength of media is within a clinically acceptable range. However, there is no clear consensus regarding what the minimum shear bond strength should be, with some reports suggesting a range of 13-21 MPa [38] and others 6-8 $\mathrm{MPa}$ [39]. The average shear strength of all composites tested in this study were $>6 \mathrm{MPa}$, considered by Reynolds and Von Frauhofer [39] and others to be appropriate for routine clinical use. Mean values of shear strength were similar to previous studies $[40,41]$ and were within the clinically acceptable bond strength range. However, in this study, the Transbond XT and Filtek Z100 composites showed the highest bond shear strength.

Regardless the applied force, total-etch adhesive systems (Transbond XT primer and its adhesive, and Filtek Z100 and Venus Diamond and Adper Scotchbond Multi-Purpose Adhesive) had higher SBS values compared with the self-etch primer (Silorane system adhesive self-etch primer and its adhesive). This was probably because phosphoricacid etching produces rough etched enamel surfaces. Bonding brackets to such a surface results in thick and uniform resin tags that deeply penetrate enamel. On the other hand, shallower and fewer resin tags are obtained with self-etching primer systems [35, 42]. This effect is apparent in the analysis of the ARI scores; there was a trend toward reduced residual adhesive on the enamel surface when self-etch adhesives were used.

After SBS testing, it is important to determine the site of material failure and measure the ARI scores, using the system developed by Artun and Bergland [33], which helps standardize bond failure analysis. The site of failure provides information regarding the quality of the bond between the adhesive and the tooth, and between the adhesive and the bracket base [43]. By microscopic observation, debonding of the Silorane composite occurred mainly with less than half of the bonding resin remained on the tooth, (ARI $=1)$, compared with more than half (ARI $=2)$ for conventional orthodontic adhesives like Transbond XT (Table 2). These findings suggest that epoxy base resin composites (Silorane) did not bond to the bracket base as effectively as conventional orthodontic adhesives. An important requirement of an orthodontic adhesive is its 
ability to debond by clear separation from the enamel surface, leaving no residue, which facilitates debonding and subsequent polishing. Increased bond strength is associated with higher ARI scores [44]. Conversely, retention of all resin on the tooth (ARI = 3), such as occurred $60.1 \%$ of the time with the Venus Diamond composite, could be clinically advantageous compared with debonding with the concomitant removal of enamel fragments, which damages tooth surfaces. A significant correlation exists between residual adhesive and the surface appearance after cleanup [45]. Bond failure at the enameladhesive interface was suggested to be an advantage, because it reduced the amount of residual adhesive, the need for a rotary instrument for cleanup and therefore, the incidence of subsequent iatrogenic injury [45]. However, these scores depend not only on the adhesive bond strength but also on many other factors, including bracket base design, etching procedures, and adhesive type [46].

Orthodontic treatment has an inevitable influence on the enamel surface [29]. Regardless of the composite used, some grooves are present in teeth after bracket debonding and resin removal [29]. Enamel surface alterations after bracket removal are particularly important for the outer layer of enamel, which contains more minerals and fluoride than the deeper layers [29]. Damage to the enamel surface may lead to decreased enamel resistance and an increased risk of decalcification [32]. In this study, the final roughness did not appear to be influenced by the polymerization shrinkage and physical stresses of the specific composite used. Thus, the main factor determining the final roughness was that the teeth were finished with a multilaminated carbide bur (Table 1), although the tooth enamel was not returned the smoothness present before of bracket bonding (Table 1). The values for enamel roughness after finishing were similar or lower to those found in another study [25] that used similar methodology in sound tooth enamel. Thus, the enamel roughness found after finishing is acceptable. Furthermore, residual adhesive could be removed with minimal damage to the enamel by the careful use of a tungsten carbide bur [47]. Considering the biochemical factors involved in dental caries development, higher concentrations of insoluble polysaccharides can cause a shift in demineralization [48]. When combined with orthodontic treatment, the mechanical retention of foods containing insoluble polysaccharides may increase roughness in areas near those covered by the bracket. Thus, high roughness values were not found in this study in the areas of sound enamel not covered by brackets (Table 1).

Significant differences in the shear strength after of metal brackets were found among different dental composites (1) and in the surface roughness between the areas of sound enamel and the areas that were finished after debonding of metal brackets (2). The low shrinkage composites achieved low but acceptable SBS results. Evaluation of the surface roughness of enamel after finishing showed no advantages or disadvantages to any of the bonding materials tested using the methods employed in this study. However, other factors, such as the application of force, biofilm retention, micro leakage, and light reflection should be tested in future studies of low shrinkage composites.

\section{Conclusions}

Low-shrinkage composites produced sufficient in vitro SBS values. However, these values were lower than those of the Transbond XT and Filtek Z100 composites. Roughness differed between the sound enamel and the enamel finished with the carbide bur system. 
However, the enamel finished using the carbide bur system had no difference in surface roughness with any of the different composites tested.

\section{Authors' contributions}

GMP, ARA, FSR and AGJ participated in performing the experiments. SBB, ABC and MBL contributed to the writing of the manuscript. EFC performed the statistical analysis. RDG conceived of the study, participating in its design and coordination, helping to drafting the manuscript. All the authors have read and approved the final manuscript.

\section{Author details}

${ }^{1}$ Department of Restorative Dentistry, School of Dentistry, University of North Parana - UNOPAR, Rua Marselha 183, Londrina CEP 86041-140, PR, Brazil. ${ }^{2}$ Department of Restorative Dentistry, Piracicaba Dental School, State University of Campinas - UNICAMP, Piracicaba, Av. Limeira, 901, Piracicaba CEP 13414-903, SP, Brazil. ${ }^{3}$ Department of Restorative Dentistry, School of Dentistry, State University of Londrina - UEL, Rua Pernambuco, 540, CEP 86020-070 Londrina, PR, Brazil.

\section{Acknowledgements}

We thank the State University of Londrina for the use of the surface roughness tester and engineer Marcos Blanco Cangiani (State University of Campinas-Piracicaba Dental School) for assistance with the methods.

\section{Competing interests}

The authors declare that they have no competing interests.

Received: 14 April 2016 Accepted: 7 June 2016

Published online: 10 June 2016

\section{References}

1. Newman G. Epoxy adhesives for orthodontic attachments: progress report. Am J Orthod. 1965;51(12):901-12.

2. Sabatoski MA, Maruo IT, Camargo ES, Filho OG, Tanaka OM, Maruo H. Influence of natural bovine enamel roughness on bond strength after etching. Angle Orthod. 2010;80(3):562-9.

3. Buonocore M. A simple method of increasing the adhesion of acrylic filling material to enamel surfaces. J Dent Res. 1955;34(6):849-53.

4. Al Shamsi A, Cunninghan JL, Lamey PJ, Lynch E. Shear bond strength and residual adhesive after orthodontic bracket debonding. Angle Orthod. 2006;76(4):694-9.

5. Arhun N, Arman A, Sesen C, Karabulut E, Korkmaz Y, Gokalp S. Shear bond strength of orthodontic brackets with 3 self-etch adhesives. Am J Orthod Dentofacial Orthop. 2006;129(4):547-50.

6. Bishara SE, Ajlouni R, Laffoon JF, Warren JJ. Comparison of shear bond strength of two self-etch primer/adhesive systems. Angle Orthod. 2006;76(1):123-6.

7. Pithon MM, Santos RL, Oliveira MV, Ruellas ACO, Romano FL. Metallic brackets bonded with resin-reinforced glass ionomer cements under different enamel conditions. Angle Orthod. 2006;76(4):700-4.

8. Vicente A, Bravo LA, Romero M, Ortíz AJ, Canteras M. Effects of 3 adhesion promoters on the shear bond strength of orthodontic brackets: an in vitro study. Am J Orthod Dentofacial Orthop. 2000;129(3):390-5.

9. Godoy-Bezerra J, Vieira S, Oliveira JHG, Lara F. Shear bond strength of resin-modified glass ionomer cement with saliva present and different enamel pretreatments. Angle Orthod. 2006;76(3):470-4.

10. Bishara SE, Olsen M, Von Wald LV. Comparisons of shear bond strength of precoated and uncoated brackets. Am J Orthod Dentofacial Orthop. 1997;112(6):617-21.

11. Cozza P, Martucci L, De Toffol L, Penco SI. Shear bond strength of metal brackets on enamel. Angle Orthod. 2006;76(5):851-6.

12. Turgut MD, Attar N, Korkmaz Y, Gokcelik A. Comparison of shear bond strengths of orthodontic brackets bonded with flowable composites. Dent Mater J. 2011;30(1):66-71.

13. Buyuk SK, Cantekin K, Demirbuga S, Ozturk MA. Are the low-shrinking composites suitable for orthodontic bracket bonding? Eur J Dent. 2013;7(3):284-8.

14. Harris JC, Jacobsen PH, O'Doherty DM. The effect of curing light intensity and test temperature on the dynamic mechanical properties of two polymer composites. J Oral Rehabil. 1999;26(8):635-9.

15. Nakamichi I, Iwaku M, Fusayama T. Bovine teeth as possible substitutes in the adhesion test. J Dent Res. 1983:62(10):1076-81.

16. Oesterle LJ, Shellhart WC, Belanger GK. The use of bovine enamel in bonding studies. Am J Orthod Dentofacial Orthop. 1998;114(5):514-9.

17. Baize S, Leroy EM, Georges AJ, Georges-Courbot MC, Capron M, Bedjabaga I, Lansoud-Soukate J, Mavoungou E. Inflammatory responses in Ebola virus-infected patients. Clin Exp Immunol. 2002;128(1):163-8.

18. Mizrahi E. Enamel demineralization following orthodontic treatment. Am J Orthod. 1982;82(1):62-7.

19. Thalacker C, Miura A, De Feyter S, De Schryver FC, Wurthner F. Hydrogen bond directed self-assembly of coresubstituted naphthalene bisimides with melamines in solution and the graphite interface. Org Biomol Chem. 2005;3(3):414-22

20. Aleixo AR, Guiraldo RD, Fugolin AP, Berger SB, Consani RL, Correr AB, Gonini-Júnior A, Lopes MB. Evaluation of contraction stress, conversion degree, and cross-link density in low-shrinkage composites. Photomed Laser Surg. 2014;32(5):267-73.

21. Machado FW, Borges FB, Cenci MS, Moraes RR, Boscato N. Effect of filling technique on the bond strength of methacrylate and silorane-based composite restorations. Braz Oral Res [online]. 2016;30(1):e44. 
22. Navarra CO, Cadenaro M, Armstrong SR, Jessop J, Antoniolli F, Sergo V, Di Lenarda R, Breschi L. Degree of conversion of filtek silorane adhesive system and clearfil se bond within the hybrid and adhesive layer: an in situ raman analysis. Dent Mater. 2009;25(9):1178-85.

23. Guiraldo RD, Consani S, Consani RL, Berger SB, Mendes WB, Sinhoreti MA, Correr-Sobrinho L. Comparison of silorane and methacrylatebased composite resins on the curing light transmission. Braz Dent J. 2010;21(6):538-42.

24. Weinmann W, Thalacher C, Guggenberger R. Siloranes in dental composites. Dent Mater. 2005;21(1):68-74.

25. Marchesi G, Breschi L, Antoniolli F, Di Lenarda R, Ferracane J, Cadenaro M. Contraction stress of low-shrinkage composite materials assessed with different testing systems. Dent Mater. 2010;26(10):947-53.

26. Brauchli LM, Baumgartner EM, Ball J, Wichelhaus A. Roughness of enamel surfaces after different bonding and debonding procedures: an in vitro study. J Orofac Orthop. 2011;72(1):61-7.

27. Zarrinia K, Eid NM, Kehoe MJ. The effect of different debonding techniques on the enamel surface: an in vitro qualitative study. Am J Orthod Dentofacial Orthop. 1995;108(3):284-93.

28. Diedrich P. Enamel alterations from bracket bonding and debonding: a study with the scanning electron microscope. Am J Orthod. 1981;79(5):500-22.

29. Faria-Júnior ÉM, Guiraldo RD, Berger SB, Correr AB, Correr-Sobrinho L, Contreras EF, Lopes MB. In-vivo evaluation of the surface roughness and morphology of enamel after bracket removal and polishing by different techniques. Am J Orthod Dentofacial Orthop. 2015;147(3):324-9.

30. Yamada R, Hayakawa T, Kasai K. Effect of using self-etching primer for bonding orthodontic brackets. Angle Orthod. 2002;72(6):558-64.

31. Campbell PM. Enamel surfaces after orthodontic bracket debonding. Angle Orthod. 1995;65(2):103-10.

32. Karan S, Kircelli BH, Tasdelen B. Enamel surface roughness after debonding. Angle Orthod. 2010;80(6):1081-8.

33. Artun J, Bergland S. Clinical trials with crystal growth conditioning as an alternative to acid-etch enamel pretreatment. Am J Orthod. 1984;85(4):333-40.

34. Zavala-Alonso V, Rodríguez-Cruz C, Martínez-Castañón GA, Loyola-Rodríguez JP, Patiño-Marín N, García-Godoy F. Shear bond strength evaluation of orthodontic brackets bonded to fluorotic teeth with a self- etching primer and a new generation of color bonding. J Adhes. 2014;90:778-86.

35. Abdelnaby YL, Al-Wakeel Eel S. Effect of early orthodontic force on shear bond strength of orthodontic brackets bonded with different adhesive systems. Am J Orthod Dentofacial Orthop. 2010;138(2):208-14.

36. Ogaard B. Prevalence of white spot lesions in 19-year-olds: a study on untreated and orthodontically treated persons 5 years after treatment. Am J Orthod Dentofacial Orthop. 1989;96(5):423-7.

37. de Araujo LO, Barreto O, de Mendonça AA, França R. Assessment of the degree of conversion in light-curing orthodontic resins with various viscosities. Appl Adhes Sci. 2015;3:26.

38. Zeppieri I, Chung C, Mante F. Effect of saliva on shear bond strength of an orthodontic adhesive used with moisture-insensitive and self-etching primers. Am J Orthod Dentofacial Orthop. 2003;124(4):414-9.

39. Reynolds IR, Von Fraunhofer JA. A review of direct orthodontic bonding. Br J Orthod. 1975;2:143-6.

40. RockW, Abdullah M. Shear bond strengths produced by composite and compomer light cured orthodontic adhesives. J Dent. 1997;25(3-4):243-9.

41. Tang A, Bjrkman L, Adamczak E, Andlin-Sobocki A, Ekstrand J. In vitro shear bond strength of orthodontic bondings with and without liquid resin. Acta Odontol Scand. 2000;58(1):44-8.

42. Fjeld $M, \varnothing$ gaard B. Scanning electron microscopic evaluation of enamel surfaces exposed to 3 orthodontic bonding systems. Am J Orthod Dentofacial Orthop. 2006;130(5):575-81.

43. Fox NA, McCabe JF, Buckley JG. A critique of bond strength testing in orthodontics. Br J Orthod. 1994;21:33-43.

44. Carstensen W. Effect of reduction of phosphoric acid concentration on the shear bond strengths of brackets. Am J Orthod Dentofacial Orthop. 1995;108(3):274-7.

45. Sessa T, Civović J, Pajević T, Juloski J, Beloica M, Pavlović V, Glisić B. Scanning electron microscopic examination of enamel surface after fixed orthodontic treatment: in vivo study. Srp Arh Celok Lek. 2012;140(1-2):22-8.

46. O'Brien RD, Watts DC, Read MJF. Residual debris and bond strength — is there a relationship? Am J Orthod Dentofacial Orthop. 1988;94(3):222-30.

47. Ferreira FG, Nouer DF, Silva NP, Garbui IU, Correr-Sobrinho L, Nouer PR. Qualitative and quantitative evaluation of human dental enamel after bracket debonding: a noncontact three-dimensional optical profilometry analysis. Clin Oral Investig. 2014;18(7):1853-64.

48. Tenuta LM, Lima JE, Cardoso CL, Tabchoury CP, Cury JA. Effect of plaque accumulation and salivary factors on enamel demineralization and plaque composition in situ. Pesqui Odontol Bras. 2003;17(4):326-31.

\title{
Submit your manuscript to a SpringerOpen ${ }^{\circ}$ journal and benefit from:
}

\author{
- Convenient online submission \\ - Rigorous peer review \\ - Immediate publication on acceptance \\ - Open access: articles freely available online \\ - High visibility within the field \\ - Retaining the copyright to your article
}

Submit your next manuscript at $\boldsymbol{\nabla}$ springeropen.com 